\title{
Research
}

Freda Mold, Simon de Lusignan, Aziz Sheikh, Azeem Majeed, Jeremy C Wyatt, Tom Quinn, Mary Cavill, Christina Franco, Umesh Chauhan, Hannah Blakey, Neha Kataria,

Theodoros N Arvanitis and Beverley Ellis

\section{Patients' online access to their electronic health records and linked online services:}

\author{
a systematic review in primary care
}

\begin{abstract}
\section{Background}

Online access to medical records by patients can potentially enhance provision of patient-centred care and improve satisfaction. However, online access and services may also prove to be an additional burden for the healthcare provider.

Aim

To assess the impact of providing patients with access to their general practice electronic health records (EHR) and other EHR-linked online services on the provision, quality, and safety of health care.
\end{abstract}

\section{Design and setting}

A systematic review was conducted that focused on all studies about online record access and transactional services in primary care.

\section{Method}

Data sources included MEDLINE, Embase,

CINAHL, Cochrane Library, EPOC, DARE, King's Fund, Nuffield Health, PsycINFO, OpenGrey (1999 2012). The literature was independently screened against detailed inclusion and exclusion criteria; independent dual data extraction was conducted, the risk of bias (RoB) assessed, and a narrative synthesis of the evidence conducted.

\section{Results}

A total of 176 studies were identified, 17 of which were randomised controlled trials, cohort, or cluster studies. Patients reported improved satisfaction with online access and services compared with standard provision, improved selfcare, and better communication and engagement with clinicians. Safety improvements were patient-led through identifying medication errors and facilitating more use of preventive services. Provision of online record access and services resulted in a moderate increase of e-mail, no change on telephone contact, but there were variable effects on face-to-face contact. However, other tasks were necessary to sustain these services, which impacted on clinician time. There were no reports of harm or breaches in privacy.

\section{Conclusion}

While the RoB scores suggest many of the studies were of low quality, patients using online services reported increased convenience and satisfaction. These services positively impacted on patient safety, although there were variations of record access and use by specific ethnic and socioeconomic groups. Professional concerns about privacy were unrealised and those about workload were only partly so.

\section{Keywords}

electronic health records; online access; patient

records; primary care; systematic review.

\section{INTRODUCTION}

Online access to medical records by patients has the potential to enhance provision of patient-centred care and may improve patient satisfaction. However, it may also prove to be an additional burden for the healthcare provider. ${ }^{1,2}$ Proposals to link personal records from multiple health providers into a single online record have also not been widely implemented. ${ }^{3,4}$ Online services may also offer patients greater convenience and satisfaction, although concerns remain about privacy and confidentiality.

While significant progress has been made in other jurisdictions, most notably in some sectors of the US health system, 5,6 there has been more limited progress in the UK, at least in part reflecting professional concerns about security, privacy, ${ }^{7-11}$ legal constraints, ${ }^{12}$ and the potential pitfalls of allowing access to children's records. ${ }^{13}$

Pilot studies demonstrate the feasibility of providing online access. ${ }^{14,15}$ 'Online access' is generally subdivided into access to the medical record itself; provision of e-mail or an equivalent messaging service through a portal; and 'transactional services' such as requesting a repeat prescription or booking an appointment. In the US, Kaiser Permanente has had success in securing two-thirds of its 3.4 million members to sign up for online appointment booking, viewing test results, and e-mail. ${ }^{16}$ Similarly, the Veterans Health Administration has also registered large numbers online, with over 600000 users making over 20 million 'visits' over the internet by 2008; with the most popular service being online repeat prescription requests; ${ }^{17}$ but uptake on this scale has yet to be replicated in the UK.

The policy context for this review is one where the English NHS (Department of Health/NHS England) intends patients to have free access to their health record by $2015 .{ }^{18}$ Guidance developed by early innovators of online access in primary care was not widely adopted, ${ }^{19}$ and has recently been superseded. ${ }^{20}$

The aim of this review was to assess the
F Mold, BSc, PhD, lecturer, integrated care; S de Lusignan, BSc(Hons), MSc, MD, FBCS, CITP, FHEA, FACHI, FRCGP, professor of primary care and clinical informatics; T Quinn, MPhil, RN, FRCN, FESC, FAHA, professor of clinical practice and associate dean, Health and Medical Strategy; N Kataria, MBChB, honorary researcher, University of Surrey, Guildford. A Sheikh, OBE, BSc, MSc, MD, FRCGP, FRCP, FRCPE, professor of primary care research and development and co-director, Centre for Population Health Sciences, The University of Edinburgh, Edinburgh. A Majeed, MD, FRCP, FRCGP, FFPH, professor

of primary care, Imperial College London, London. JC Wyatt, DM, FRCP, leadership chair in eHealth Research, Leeds Institute of Health Sciences, University of Leeds, Leeds. M Cavill, BA (Hons), PGCert, MA, information officer, Clinical Innovation and Research Centre, Royal College of General Practitioners, London. C Franco. postgraduate public health student, University of Dundee, Dundee. U Chauhan, MA, PhD, MRCGP. honorary senior research fellow; B Ellis, MA, PhD CITP, principal lecturer, University of Central Lancashire, Preston. H Blakey, academic primary care foundation programme doctor, St George's Hospital, London. TN Arvanitis, RT, DPhil, CEng, FRSM, professor of e-Health Innovation, Institute of Digital Healthcare, University of Warwick, Coventry.

\section{Address for correspondence}

Simon de Lusignan, Professor of Primary Care and Clinical Informatics, Department of Health Care Management and Policy, University of Surrey, Guildford, GU2 7XH, UK.

E-mail: s.lusignandsurrey.ac.uk

Submitted: 7 May 2014; Editor's response: 6 June 2014; final acceptance: 1 July 2014. (c)British Journal of General Practice

This is the full-length article (published online 2 Mar 2015) of an abridged version published in print. Cite this article as: Br J Gen Pract 2015; DOI: 10.3399/bjgp15X683941 


\section{How this fits in}

Online services have been successfully piloted by large American organisations (such as Kaiser Permanente) but this success has not been replicated in the UK. This study found that patient satisfaction improved through enabling better selfcare. Clinicians had concerns about the additional burden and workload from online access but evidence found their fears were only partly realised. There is a lack of good quality research in these areas in the UK; especially research that measures impact (such as health outcomes).

impact of providing patients with access to their general practice electronic health records (EHR) and other EHR-linked online services on the provision, quality, and safety of health care.

\section{METHOD}

This systematic review was conducted following Cochrane guidelines, ${ }^{21}$ and complies with the Preferred Reporting Items for Systematic reviews and MetaAnalyses (PRISMA) framework. ${ }^{22}$ The protocol for this review has already been published, including details of the key research questions, and inclusion and exclusion criteria. ${ }^{23,24}$ The study aims were structured in a systematic way, using the elements of a clinical question, including population, intervention, comparator, and outcome (Box 1). ${ }^{25}$

\section{Box 1. PICO criteria}

\section{Population}

Defined as users or non-users of online record access and remote contact services, including both patients (including carers and children) and clinicians/support staff in primary care

\section{Intervention}

Any intervention related to online access and services used in primary care. The types of intervention will be classified by whether they are principally designed to impact on patients or clinicians, or are technical in nature. Also whether online access is primarily synchronous or asynchronous

\section{Comparator}

Any comparison including usual care

\section{Outcomes}

Attributes of the user, use of access and services on quality and safety, and impact of use on patient and professional groups. Thus includes professional-patient relationships, access, satisfaction, and workload/workflow, and any possible impact on health outcomes. No limits were placed on how these outcomes were measured within specific intervention timescales

\section{Study selection, screening, data extraction, and risk of bias assessment}

Papers were screened by three authors using a detailed inclusion and exclusion guide and selection flowchart to identify relevant papers. ${ }^{23}$ Results from these searches, and all decisions regarding inclusion and exclusion were stored using Endnote (v.7.2.1.4) (Table 1). Disagreement was resolved by reviewing and discussing full text versions. The included papers were then sourced and full text papers were divided across the review team for review. The review team were volunteers who had expressed interest in joining Working Group 7 land evaluation of the evidence) of a larger Royal College of General Practitioners' exercise to define a Road Map for providing patients online access to their medical records. ${ }^{20}$ A purposeful sample of academics, practitioners, and patient representatives with relevant expertise were recruited. Each reviewer was provided with a data extraction form to ensure consistency. Two exercises were conducted to test and refine the electronic and web-based data extraction forms. All reviews were independently checked by a third reviewer.

The data extraction form also included a risk of bias (RoB) form lavailable from the authors on request) for each paper, to capture study design limitations and offer insight into future study design. The RoB assessment was grouped into six domains: sequence generation, allocation concealment, blinding, incomplete outcome data, selective reporting, and other bias. It was intended to eventually use the Grading of Recommendations Assessment, Development and Evaluation (GRADE) instrument to assess the strength of evidence across particular study outcomes. ${ }^{26-28}$

\section{Analysis considerations}

Most formal testing of hypotheses within studies used $t$-tests and $\chi^{2}$ tests. Because of the variation in study designs, no single analysis method was undertaken across all the studies. Where necessary, all relevant statistical information is provided for each paper. A meta-analysis could not be undertaken because trials were not sufficiently homogeneous in terms of primary outcome measures to provide a meaningful summary. Further analysis, such as sensitivity or subgroup analysis, could not be undertaken.

\section{RESULTS}

\section{Included studies and risk of bias}

From the 176 papers sourced, only 17 


\section{Table 1. Study characteristics}

\begin{tabular}{lccc} 
Study type & Country & $\boldsymbol{n}$ & Reference \\
\hline $\begin{array}{l}\text { Randomised control trials lincluding one randomised } \\
\text { control pilot study) }\end{array}$ & US & 5 & $29,31,35,36,37$ \\
\cline { 2 - 4 } & Norway & 3 & $30,33,34$ \\
\cline { 2 - 4 } & UK & 1 & 32 \\
\hline $\begin{array}{l}\text { Cohort studies lincluding one retrospective cohort study, } \\
\text { one cross-sectional cohort study, one retrospective cohort, } \\
\text { and matched-control study) }\end{array}$ & US & 4 & $38,39,40,41$ \\
\hline $\begin{array}{l}\text { Cluster randomised control trials } \\
\text { Quasi-experimental trial }\end{array}$ & US & 3 & $42,43,44$ \\
\hline & US & 1 & 45 \\
\hline
\end{tabular}

papers were experimental in design, or cohort studies. Nine studies were randomised controlled trials ${ }^{29-36}$ lincluding one randomised control pilot study with qualitative element), ${ }^{37}$ and four were cohort studies $^{38}$ (including one retrospective cohort study, ${ }^{39}$ one cross-sectional cohort study, ${ }^{40}$ one retrospective cohort and matched controlled study). ${ }^{41}$ Three were cluster randomised control trials. ${ }^{42-44}$ One study was defined as using a quasi-experimental non-randomised design. ${ }^{45}$ Most of these studies originated from the US ( $n=13)$, with three studies being undertaken in Norway, and only one from the UK. Further study characteristics are summarised in Table 1. Included studies were based on the Oxford Centre for Evidence-based Medicine Levels of Evidence, ${ }^{46}$ and represented the highquality evidence from the wider systematic review. Supplementary key findings are

\section{Table 2. Supplementary key findings}

\section{Finding}

Users of these services were more likely to be female (OR 1.15), middle aged or older, with much greater morbidity than non-users (OR 5.6)

People with Medicaid cover were less likely to use these services (OR 0.8) than people with commercial insurance

African-American, other non-white ethnicities, and females with lower socioeconomic classification were less likely to use the services

$70 \%$ of clinicians felt that online access strengthened relationships, enhanced trust, and improved decision making

Patients who used online access to test results were more satisfied than those who did not

Use of a secure messaging tool improved patient satisfaction with care from $48 \%$ to $59 \%(P=0.04)$

Patients felt themselves better able to express their concerns in writing (34\%), to communicate about difficult topics (36\%), and to send psychosocial information when using online tools versus telephone

\begin{tabular}{|c|c|c|c|}
\hline Online systems saved patients time, telephone calls, and clinic visits & Randomised control trials (and interviews) & Norway, US & 34,35 \\
\hline $\begin{array}{l}\text { About half of US patients were willing to pay for online access, and } 21 \% \text { were } \\
\text { unwilling. Of those who were willing, the median value assigned was } \$ 2 \text { per } \\
\text { message }\end{array}$ & $\begin{array}{l}\text { Randomised control trials, randomised } \\
\text { control pilot study }\end{array}$ & $\begin{array}{l}\text { Norway, US, } \\
\text { US }\end{array}$ & $33,35,37$ \\
\hline $\begin{array}{l}\text { Patients given online access to their records identified more than twice as } \\
\text { many medication list discrepancies with potential for severe harm than those } \\
\text { who did not }\end{array}$ & Cluster-randomised trial & US & 43 \\
\hline \multirow{2}{*}{$\begin{array}{l}\text { Users of online services received } 84 \% \text { of preventive care services compared } \\
\text { with } 68 \% \text { of controls, including influenza vaccine ( } 22 \% \text { versus } 14 \% \text { ) and } \\
\text { mammography ( } 49 \% \text { versus } 30 \% \text { ); children whose parents used online } \\
\text { services received } 96 \% \text { of immunisations versus } 87 \% \text { in controls. Online } \\
\text { services also facilitated health maintenance/appointment reminders }\end{array}$} & Cluster randomised control trial & US & 42 \\
\hline & Randomised control trials & UK, US & 32,36 \\
\hline $\begin{array}{l}\text { Only } 1-8 \% \text { of patients say that viewing their record online caused confusion, } \\
\text { worry, or offence }\end{array}$ & Quasi-experimental non-randomised design & US & 45 \\
\hline \multirow[t]{2}{*}{$\begin{array}{l}\text { The impact of online record access on patient use of face-to-face services } \\
\text { and telephone calls was unclear }\end{array}$} & $\begin{array}{l}\text { Randomised control trial (and interviews), } \\
\text { cohort with match controls, quasi- } \\
\text { experimental non-randomised design }\end{array}$ & $\begin{array}{l}\text { Norway, US, } \\
\text { US }\end{array}$ & $34,39,45$ \\
\hline & $\begin{array}{l}\text { Randomised control trial, randomised } \\
\text { control trial land interviews), cohort and } \\
\text { matched-control study, cluster randomised } \\
\text { control trial }\end{array}$ & $\begin{array}{l}\text { Norway, } \\
\text { Norway, US, } \\
\text { US }\end{array}$ & $30,34,41,42$ \\
\hline $\begin{array}{l}\text { Clinicians had concerns about the additional burden and workload from } \\
\text { online access but found their fears only partly realised }\end{array}$ & $\begin{array}{l}\text { Randomised control trial land patient } \\
\text { surveyl, three-part cohort study, quasi- } \\
\text { experimental non-randomised design }\end{array}$ & US, US, US & $31,38,45$ \\
\hline
\end{tabular}

$O R=$ odds ratio

\section{Study type}

Cohort with match controls

Country

Reference

cross-sectional cohort study

Cross-sectional cohort study

Randomised control trial, randomised control pilot study

Quasi-experimental non-randomised design

US

45

Cluster randomised control trial

US

44

Randomised control trial

US

35

Randomised control trials (and interviews)

US, US

34,35

40

0




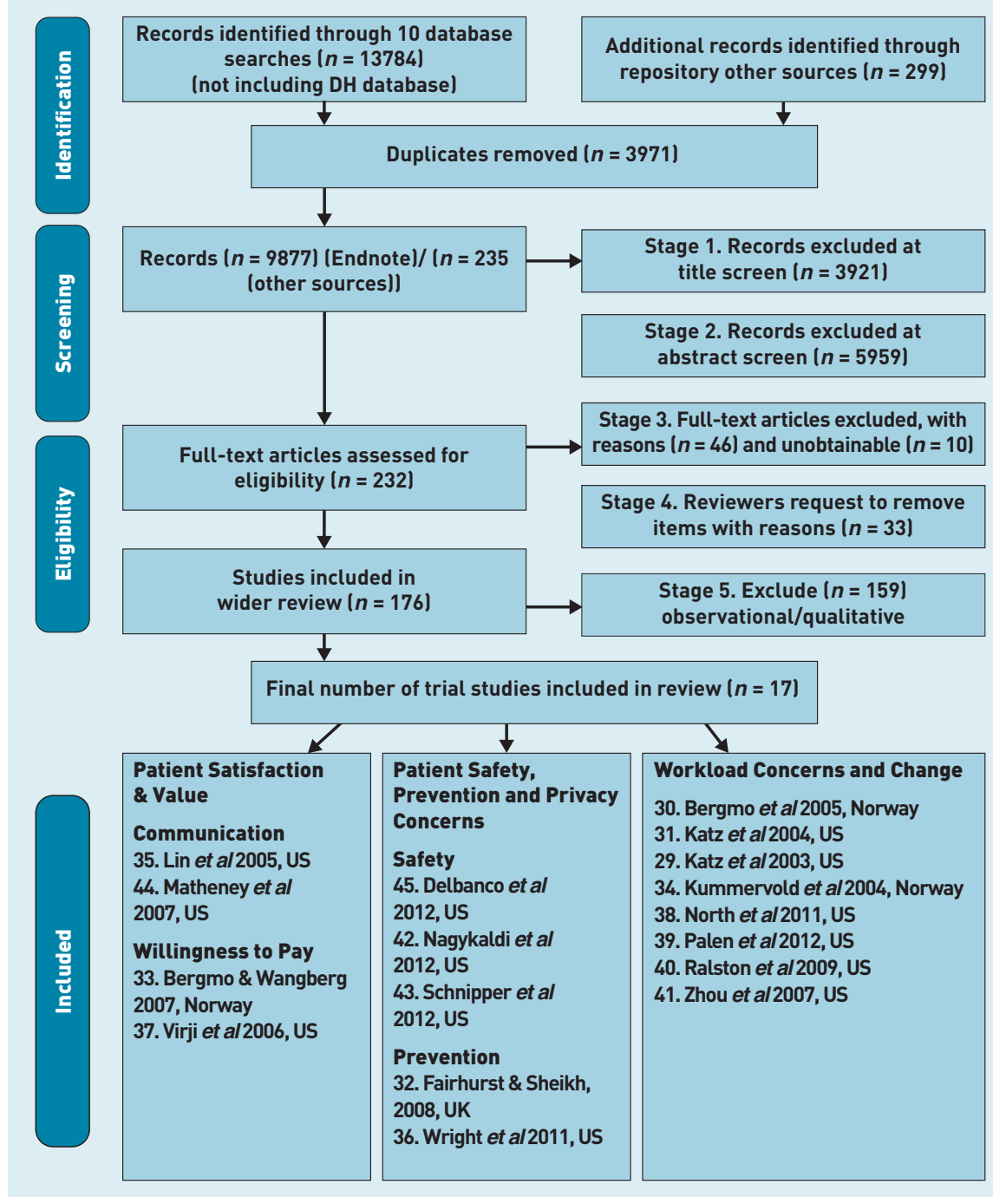

Figure 1. The Preferred Reporting items for Systematic Reviews and meta-Analysis (PRISMA) flowchart. $D H=$ Department of Health. given in Table 2. Details of the searches are presented in the Preferred reporting items for systematic reviews and meta-analyses (PRISMA) flowchart (Figure 1).

Outcomes of these studies varied, with most focusing specifically on online record access, ${ }^{39}$ or online service utilisation, ${ }^{30,34,37,40-42}$ including impact on workload, ${ }^{31,45}$ and attendance rates. ${ }^{32}$ Several focused on patient or provider satisfaction; $29,35,38,44$ two on patient safety, medication accuracy, ${ }^{43}$ and preventive reminders; ${ }^{36}$ and one study on willingness to pay for electronic communication with their GP. ${ }^{33}$ These studies were subject to RoB assessment. These studies illustrated a wide variation in their RoB and most showed a high risk of bias in more than one assessment area. Figures 2 and 3 show risk of bias tables and summary graphs.

\section{User characteristics}

Online record access and service users tended to be slightly older ( $t$-test, $P<0.001),{ }^{39}$ or middle aged (50-65 years), ${ }^{40}$ and were more likely to be female $\left(\chi^{2}\right.$. $P=0.002$ ), ${ }^{39}$ lodds ratio [OR] 1.15; 95\% confidence interval $[\mathrm{Cl}]=1.10$ to 1.19$) .40$ Users also tended to have much greater overall morbidity IOR 5.64; $95 \% \mathrm{Cl}=5.07$ to 6.28$).{ }^{40}$ Differences were also observed between insurance types, with users of messaging being less likely to be funded by Medicaid insurance than commercial insurance (OR $0.81,95 \% \mathrm{Cl}=0.68$ to 0.96$) .40$ African-American and other non-white ethnicities ${ }^{29}$ (42.9\% and $50.3 \%$, respectively, $P<0.01$ ) were less likely than white and Asian patients to use online access $173.6 \%$ and $93.4 \%$, respectively); and so were females of lower socioeconomic status. ${ }^{37}$ Further information on each of the included studies is available from the authors on request.

\section{Patient satisfaction and value}

Self-care. Patient satisfaction improved through enabling better self-care. The introduction of a system which enabled patients to view their test results, manage their medication list, and have secure messaging with their practice, resulted in $80 \%$ of responders ( $n=448 / 560$ ) saying the system facilitated their participation in their own care. ${ }^{42}$ Another post-intervention survey found that $77-87 \%$ of 5391 patients across three sites who had online access to visit notes felt more in control of their care. ${ }^{45}$ Of the clinician responses, 73 out of $104(70 \%)$ felt that enabling patients to read their own notes online strengthened relationships, enhanced trust, and improved decision making. ${ }^{45}$

Online communication. Several trials showed that online access to records and services improved communication. ${ }^{34,35,44}$ Patients were more satisfied with automated communication of test results (OR 2.35: $95 \% \mathrm{Cl}=1.05$ to $5.25 ; \quad P=0.03$ ) and with online information about their treatment or condition IOR $3.45 ; 95 \% \mathrm{Cl}=1.30$ to 9.17 ; $P=0.02)$; compared with those who accessed this information in person or by telephone. ${ }^{44}$ One trial measuring the frequency of portal use and satisfaction with secure messaging found that patients' communication with their clinic improved; with $44 \%(n=77 / 174)$ in the intervention arm compared with $12 \%$ I $\left.n=18 / 146 ; \chi^{2}=38.8, P<0.001\right)$ in the control group. Use of the messaging portal also resulted in higher satisfaction with overall care $59 \%(n=103 / 174)$ in the intervention group compared with $48 \% \quad(n=78 / 162$; $\left.\chi^{2}=4.1, P=0.04\right){ }^{35}$ 


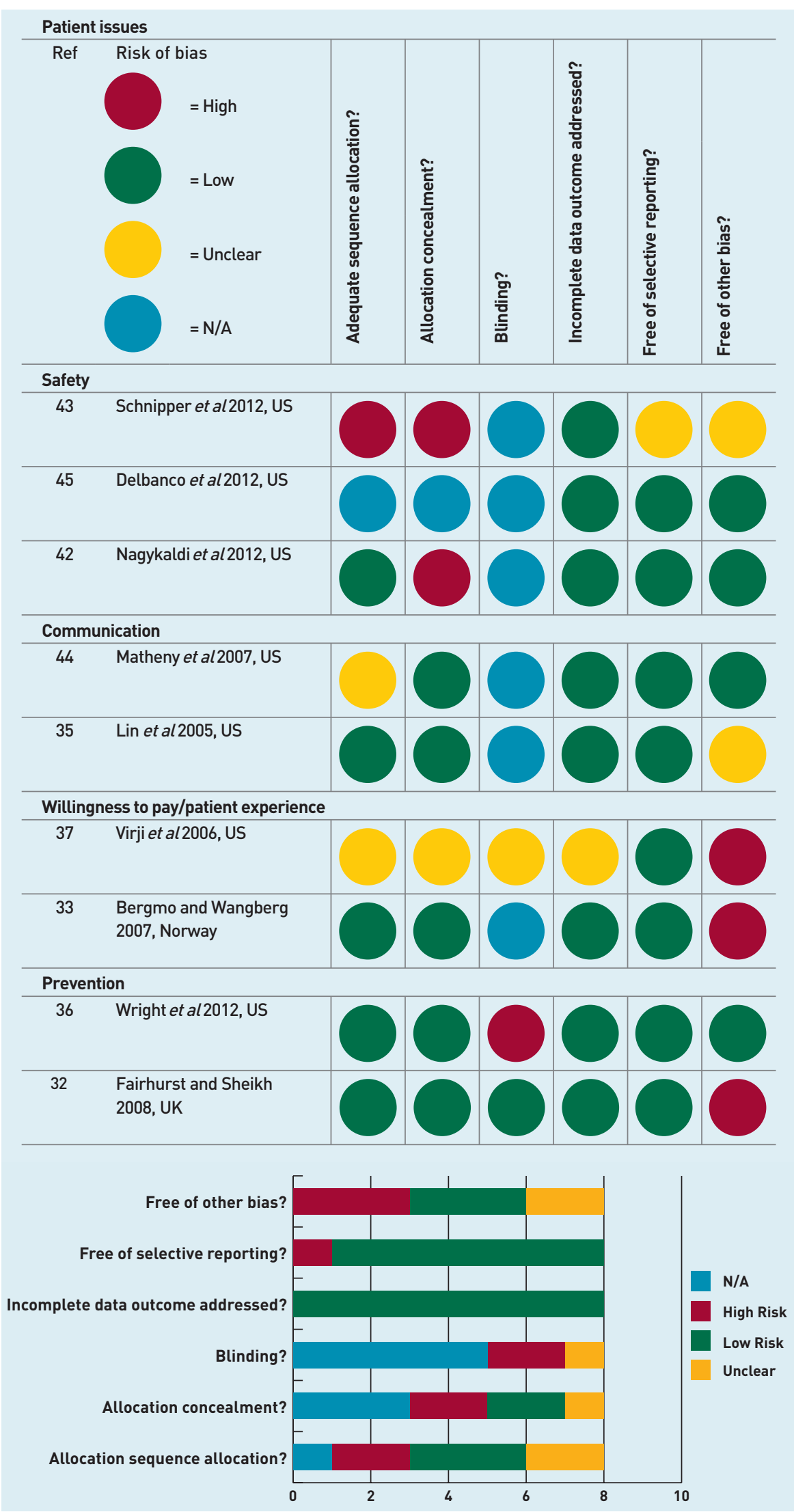

Figure 2. Patient issues risk of bias table and summary graph.
The contents, tone, and timeliness of online messaging to clinicians also improved communication and satisfaction. Some patients (34\%, $n=68 / 200$ ) felt better able to express their concerns in writing; $36 \%(n=72 / 200)$ felt it easier to communicate about difficult topics), ${ }^{34}$ and felt that they would be more likely to send psychosocial information via online systems than by telephone..$^{35}$ Online services, such as online communication, also saved patients time; however, time in these trials was not quantified, ${ }^{34,35}$ and was found not to necessarily help reduce the number of telephone calls and clinic visits. ${ }^{35}$ In addition, patients' satisfaction with their primary care providers' general communication skills may not necessarily improve with the adoption of online access and services. ${ }^{44}$ Research into the communication experience for patients was largely at low risk of bias in several areas, including allocation concealment, addressing all outcome data, and being free from reporting bias (Figure 2) ${ }^{35,44}$

How patients valued online access and services. Many patients would not be willing to pay for, or only placed a low value on, online services, such as online communication with clinicians. ${ }^{33,35,37}$ In one US study, only $51 \%$ of study participants ( $n=77 / 151$ ) expressed a willingness to pay for electronic contact with their clinician, and $21 \%(n=31 / 151)$ expressed unwillingness. Those who had communicated with their clinician electronically for at least a year had a lower willingness to pay than those who did not have access $(P=0.0028) .{ }^{33}$ Two further studies reported similar findings, with less than half of participants $142 \%$, $\mathrm{n}=111 / 266),{ }^{37}$ and $48 \% \quad(n=162 / 341),{ }^{35}$ reporting an unwillingness to pay a fee to have e-mail or online messaging with their clinician. The value assigned to this service was low: a median of \$2 (mean \$4.10) per message, ${ }^{35}$ and another stating either $€ 0$, $€ 6$, or $€ 12 .{ }^{33}$ Future research into willingness to pay, needs to be better designed, as research presented here is classified as either unclear or at high risk of bias (Figure 2). ${ }^{33,35}$

\section{Patient safety, prevention, and privacy} concerns

Patient safety was largely improved through patients identifying errors in their medication list. ${ }^{43}$ Patients given access to their medication list online corrected more than twice as many medication discrepancies with potential for severe harm ( 0.03 versus 0.08 per patient, adjusted risk ratio $0.31,95 \% \mathrm{Cl}=0.10$ to $0.92 ; P=0.04) .43$ Online access to consultation notes was also found to increase reported medication 

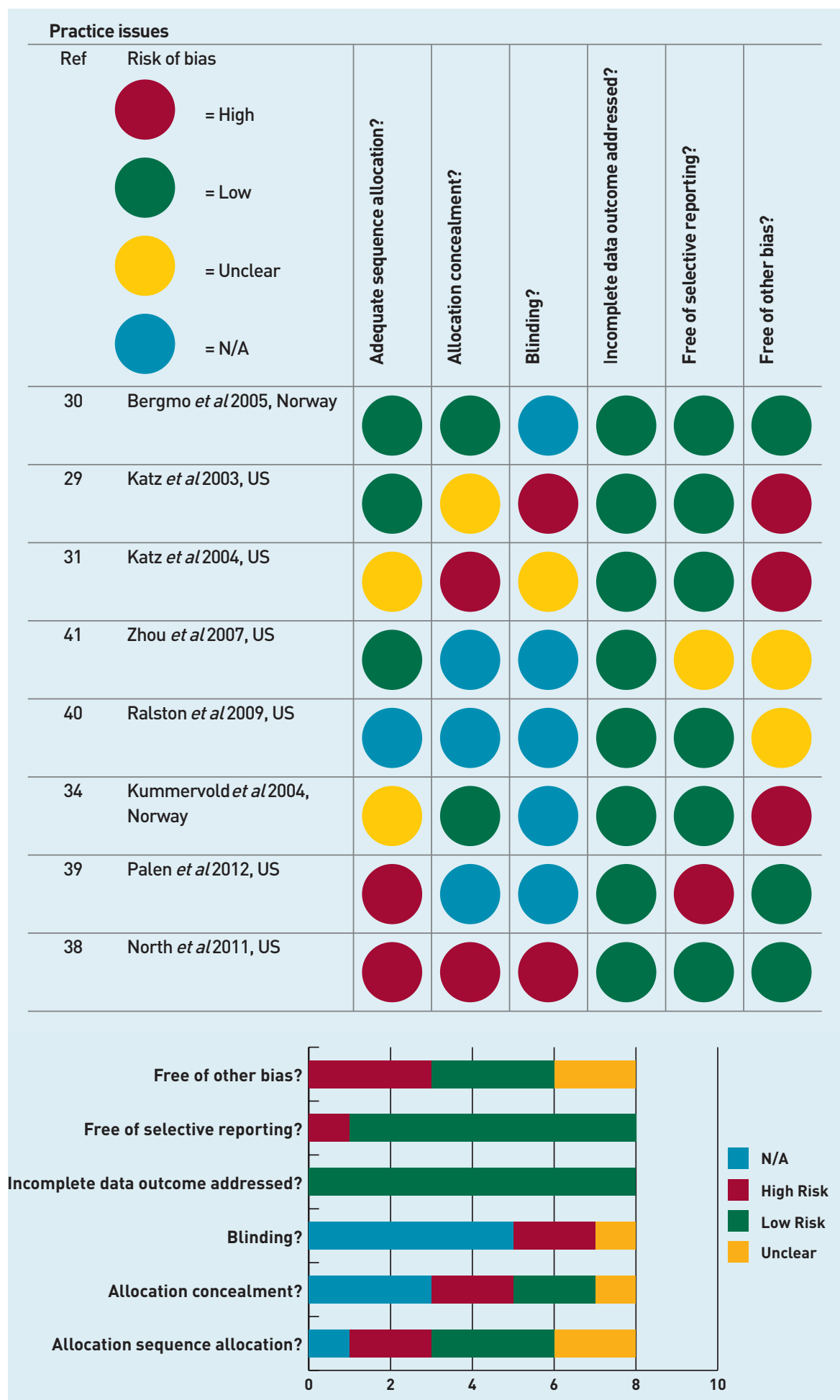

Figure 3. Practice issues risk of bias table and summary graph. adherence as $60-78 \%$ ( $n=5391)$ of patients taking medications reported increased adherence. ${ }^{45}$

Online services facilitated uptake of preventive care services by providing prevention or health maintenance reminders. ${ }^{36,42}$ Nearly all (84.4\%) patients in the intervention group received all recommended preventive services, compared with $68 \%$ of controls $(n=384$, $P<0.0001)$. Children in the intervention group received $95.5 \%$ of immunisations compared with $87.2 \%$ in the control arm $l n=105$ parents; $P=0.044) .42$ Patients provided with online prompts were significantly more likely to receive influenza vaccines $(22.0 \%$, $n=50 / 227$ versus $14.0 \%$ control; $P=0.018$ ); and undergo mammography than control groups $(48.6 \%, n=51 / 105$ versus $29.5 \%$; $P=0.006)$. No significant improvement was noted in uptake rates of other screening tests. ${ }^{36}$

Only $1-8 \%(n=5391)$ of patients stated that viewing consultation notes caused confusion, worry, or felt offended with note comments. ${ }^{45}$ Similarly, clinicians acknowledged their fears about potentially offending or worrying patients; however, these concerns did not materialise in practice. ${ }^{45}$ The studies about medication safety (inevitably) lacked allocation concealment and these papers reported blinding was not applicable to their study methods. ${ }^{42,43,45}$ The prevention outcomes studies had low risk of bias (Figure 3). ${ }^{32,36}$

\section{Workload}

Workload concerns. Clinicians had concerns about the additional burden and workload from online access but found their fears only partly realised. ${ }^{38,45}$ Clinicians involved in an initiative promoting e-mail thought e-mail was useful for answering patients' non-urgent medical questions (81.8\%, $n=43$ intervention versus $61.4 \%$, $n=46$ control; $P=0.06$ ) and helpful in managing patients' administrative concerns 186.0\%, $n=43$ intervention versus $58.0 \%$, control $n=46$; $P=0.05$ ). ${ }^{29}$ However, a few intervention clinicians felt that e-mails were too lengthy $(14.6 \%, n=43 ; P=0.04)$ or were concerned about incomplete information $(10 \%, n=43 ; P=0.11)$. In one cohort study about the implementation of a video to support the use of a patient's portal, during office visits 12 of 13 (92\%) support staff agreed that it was easy to use, and six (46\%) agreed that the technology did not take up more time. ${ }^{38}$

Effect of online access on face-toface consultations. Online access has an inconsistent effect on face-to-face consultations, which increased in some studies, $34,39,45$ and went down in others. ${ }^{30,34,41,42}$ Findings from four randomised controlled trials indicated the reduction of face-toface consultations, while findings from other study designs (cohort and quasiexperimental trials) found an increase. Clinicians ( $n=99$ ) concerned that access to 
open notes would lengthen visits, reported a minor rise in consultation rates across three study sites (0-8\%), and spent more time addressing patients' questions outside of visits (0-8\%). Clinicians also reported changes in how they recorded clinical information with between 3\% and 36\% of clinicians ( $n=99$ ) changing record content to allow for online access; and 0-21\% reporting taking more time writing notes. ${ }^{45}$ In a post-intervention survey, a significant difference was found in time spent writing or dictating notes between practice size, with four out of 37 clinicians (10.8\%) in smaller practices spending more time writing notes compared with seven out of 24 clinicians (29.2\%) in larger practices $(P=0.019) .{ }^{45}$ Finally, $59-62 \%$ of patients ( $n=5561$ ) thought they should be able to add comments to their consultation notes, such as approving the notes' contents.

Four studies found a reduction of office visits by patients using a messaging system. ${ }^{30,34,41,42}$ In one randomised controlled trial the consulting rate fell from 4.5 to 2.8 per annum in the intervention group compared with 4.3 to 3.6 per annum in the controls $(P=0.034) .{ }^{30}$ In another, patient portal users had fewer visits over the study period, compared with the control group laverage of 2.9 versus 4.3 visits; $P<0.0001) .42$ Similarly, annual visit rates decreased by $9.7 \%$ (0.23 visits per member) in a cohort study ${ }^{41}$ and in a matched-control study the decrease was $10.3 \%$, or 0.25 visits per member per year $(P<0.001)$. The control group reduction for the matched-control study was $3.7 \%$, or 0.08 visits $(P<0.003){ }^{41}$ Across-group differences between the cohort and matched-control group showed a significant difference in annual office visit rates of $6.7 \%(0.17 ; P<0.003) .{ }^{41}$

Face-to-face contact also increased in a before and after study of online test result viewing and secure messaging with clinicians. There were 87206 users of the system and 71663 non-users. Office visits rose by 0.7 per member per year $195 \%$ $\mathrm{Cl}=0.6$ to $0.7 ; P<0.001$ ) in the patient group enrolled in the online system. There was also a significant increase in rates of afterhours clinic visits (18.7 per 1000 patients per year $95 \% \mathrm{Cl}=12.8$ to $24.3 ; P<0.001)$, emergency department encounters $(11.2$ per 1000 patients per year $95 \% \mathrm{Cl}=2.6$ to 19.7; $P=0.01$ ), and hospitalisations (19.9 per 1000 patients per year $95 \% \mathrm{Cl}=14.6$ to 25.3; $P<0.001$ ) for patients who used the online system compared with non-users. ${ }^{39}$

Impact of e-mail use on patient contacts. E-mail and web-messaging sometimes increased the volume of patient contact, 29,31,41 and in other studies it remained the same, but time had to be put aside to respond to e-mails. $30,31,45$ The use of a triage-based communication tool led to increased volume of e-mail messages in the intervention group; 46 weekly e-mails per 100 scheduled visits compared with only nine in the control group at the study midpoint $(P<0.01) .{ }^{29}$ However, this increase was not sustained and the e-mail volume diminished after the initial promotion period, leading the authors to question whether e-mail use may not necessarily improve the efficiency of clinical care. ${ }^{29} \mathrm{~A}$ modest difference was also seen in the attitudes of intervention patients towards using webbased tools to address administrative and prescription issues, with $61.9 \%(n=65)$ of intervention patients, compared with 54.2\% of control patients ( $n=67)$, agreeing that they liked using the web to communicate with clinicians $(P=0.15) .{ }^{31}$

Two trials and one quasi-experimental study indicated no change in the volume of e-mail or messaging; although in these studies e-mail was clearly an established part of the doctor-patient relationship. One trial reported clinicians received one message per day for every 250 patients who were health portal users. However, only $27 \%$ were sent during clinic hours; $73 \%$ of messages were sent during nonwork hours, with $52 \%$ sent between $5 \mathrm{pm}$ and midnight. ${ }^{30}$ The volume of electronic messages did not change, in a study providing online access to 'open notes' records and was achieved with less impact on clinicians' working lives than originally anticipated. ${ }^{45}$ However, $21 \%$ of clinicians ( $n=39)$ acknowledged the need to use extra time for writing, editing, or explaining notes to their patients. ${ }^{35}$

Impact of online access on telephone calls to clinicians. Studies focusing on the impact of online services on telephone use offer mixed messages. Two studies reported a rise in telephone use, ${ }^{39,41}$ as a consequence of online access; four studies no change, ${ }^{29-31,35}$ and one study reported a decline. ${ }^{34}$

Results of a before and after study assessing online access to health records found a significant increase in the permember rates of telephone encounters, with a small rise of 0.3 per member per year $195 \% \mathrm{Cl}=0.2$ to $0.3 ; \quad P<0.001)$ in the patient group enrolled in the online system. ${ }^{39}$ Similar outcomes were found in a matched-control study, when telephone contact rates increased by $16.2 \% \quad 10.32$ 
contacts per member) in the secure messaging arm compared with $29.9 \% 10.52$ contacts per memberl for the matchedcontrol group. Across-group difference was $13.7 \%$ (0.20 contacts) and was significant $(P<0.01) .{ }^{41}$

Four studies indicated no change in telephone consultation volume. ${ }^{29-31,35}$ Two studies indicated no difference in telephone consultations between the intervention and control groups $(P \geq 0.258) ;{ }^{30,35}$ another reporting how e-mail and web-based tools did not offset either telephone volume; ${ }^{31}$ or no change in no-show visit rates. ${ }^{29}$

Only one paper suggested that telephone call volume can decline, with the intervention group seeing a reduction in the annual number of visits and telephone calls by $28 \%$ lintervention $n=74$; OR 3.19 ; $95 \%$ $\mathrm{Cl}=2.44$ to 3.94 versus control $n=92 ; \mathrm{OR}$ $4.45 ; 95 \% \mathrm{Cl}=3.60$ to $5.29 ; P<0.032$ ), and a total reduction in the number of calls to the GP of $10 \% .^{34}$

Only two areas were consistently at low RoB across workload outcomes, these being incomplete data outcomes being addressed, and being free from selective reporting in these studies. ${ }^{29-31,34,38,40}$ Several papers reported blinding was not applicable to their study methods, ${ }^{30,34,39-41}$ three reporting high $\mathrm{RoB}, 29,38$ and one had unclear blinding methods (Figure 3). ${ }^{31}$

\section{DISCUSSION}

\section{Summary}

The findings from this review are important for health systems and professionals. Evidence shows that although online access may be achievable regarding technological implementation and improvements to patient safety, there remain challenges about clinicians' adoption of systems because of workload and workflow concerns.

Users of online access and services report increased satisfaction in terms of better self-care and communication with clinicians. Online access and services also positively impacted on patient safety, especially when patients are given access to medication lists and are offered prevention or health maintenance reminders. However, there is a disparity in who accesses online records and services, with people of non-white ethnicities and those from lower socioeconomic groups potentially being disadvantaged. There is also a difference between expectations and realities of online services for both patients and clinicians. Patients anticipated empowerment and rapid responses to electronic communication and clinicians feared being overwhelmed by a new workload. However, this fear was largely unwarranted. Many administrative and non-urgent tasks appear to be more readily conducted online. They can also be conducted at times of the day convenient for patients. Although fears have been expressed about access to records being abused or causing patients greater worry, no evidence has been published to indicate what harm or privacy breech has occurred. The inter-relationship between provision of e-mail or messaging, online access, telephone, and face-to-face communication has yet to be systematically and robustly researched.

\section{Strengths and limitations}

A strength of this study was the RoB assessment that gave an indication of the likely strength of evidence and how future study design can be improved. The studies reported here largely originate from the US from large health plan-based programmes that incur a fee. There have been few randomised controlled trials examining the effectiveness of online access and services on improving health outcomes, ${ }^{47-49}$ but some work has been undertaken focusing on the impact of new technologies in relation to patient decision making and health outcomes. ${ }^{50-53}$ Like all systematic reviews, evidence was gathered from various resources from a specific time period and, as such, there may be several new studies recently published that have not been included in this review.

\section{Comparison with existing literature}

Compared with other sectors, such as for-profit companies, the adoption and integration of online technologies in UK primary care has been slow, but it is steadily growing with the introduction of new online services such as weightloss, $^{54}$ or counselling programmes, ${ }^{55,56}$ comprehensive health information systems; ${ }^{57}$ and e-mail and messaging with provider. $^{58}$

Technology has changed the nature of the patient-clinician interaction from one that was traditionally clinician-led to a more patient-centred approach. ${ }^{31,59}$ It has possibly improved trust, ${ }^{60}$ patient involvement in the clinical decision-making process, and in the quality of communication experience. ${ }^{61,62}$

Disparities in access to computers and information systems have been termed the 'digital divide'. ${ }^{31}$ However, health literacy is also an important component of being able to use online resources, ${ }^{47}$ and technology may enable new forms of clinician-patient interaction. ${ }^{48}$ 
Previous guidance developed by innovators of online access in primary care was not widely adopted. Possible explanations for limited implementation of systems to date could be due to the sociolegal context of records; security and privacy issues; language and interpretation issues; child protection and family safety issues; and patient-added data and organisational issues /such as workload, risks of litigation, training, and system processes and maintenance). ${ }^{19}$

The potential benefits of online access have yet to be fully realised in research originating from the UK; however, the lessons learned from other studies may help with future implementation.

\section{Implications for research and practice}

Online access to records may subtly change the patient-physician relationship. Patients are increasingly signing up for online services that are more convenient. Patients may no longer see the medical record as being under the sole provenance of their physician; rather as something they can view and print. This appears to be empowering. The downside is that ready access may make it easier to always consult rather than self-manage, and moves to online access provision may result in variations in service utilisation by specific population groups. Clinicians find that they have to write more carefully considered records that are more informative for their patients to read, rather than being an aide memoire for the doctor and the clinical team. Medical services may have to adapt to meet this new requirement and managers will have to learn what models of delivery increase overall workload, and what approaches might control it.

Willingness to pay studies show online access to be valued little by US research participants. In the UK's NHS willingness to pay might be less relevant. However, little work has been undertaken in the UK on accurately assessing the value patients might place on specific online services. Given this, it may be possible to undertake further research as to whether there is a place for fee paying compared with the UK norm of publicly funded health care.

Encouraging patients to access online EHR and services are a promising way to enhance safety. Further research is also needed into how patients use their access to $E H R$, and how patient-added data are used, and how they may improve care by providing insight into health beliefs and their understanding of their condition.

While there have been a number of trials conducted in the US, such evidence from the UK is scarce. Further research into the feasibility of implementing complete online access (record access and transactional services) across the UK, or in a wholesystem demonstrator, would provide valuable insight into how to implement such a service.

Research into online access and services has yet to demonstrate how health outcomes can be improved. Research is also needed for patients with specific long-term conditions, such as diabetes, which may offer greater insights regarding facilitating better health outcomes.

Other areas of further study include prevention and privacy issues involved in providing online access and services; how practices can facilitate patients' use of technologies that integrate into their existing infrastructure; and to what extent online services can replace or complement existing care. A final area is whether such systems are efficient and cost-effective. The second article from this systematic review focuses on the breadth of knowledge in this area and draws together how online record access and services may impact on the wider business process in primary care. ${ }^{63}$

Initiatives to develop policy and practice are continuing through the NHS England Patient Online programme and the Royal College of General Practitioners. The findings from this review are timely and directly relate to these initiatives, as they highlight patient perspectives, such as satisfaction, safety, prevention, and privacy concerns; and clinicians' perspectives, such as workload concerns.

Patients using online access to their EHR and services reported increased convenience and satisfaction, and these services positively impacted on patient safety. Although patients report specific benefits of record access, such as enabling better self-care and patientclinician communication, patients were unwilling to pay for these services. Prior to implementation of online systems clinicians were concerned about any possible workload rise. However, post-intervention work suggests clinicians' concerns are largely unrealised. The nature of the medical record and the role of the clinician may need to evolve to give greater value to patients and to ensure greater equity in uptake. The business model for primary care may also need to change to enable more effective utilisation of information technology in everyday practice. 


\section{REFERENCES}

1. Beard $L$, Schein $R$, Morra $D$, et al. The challenges in making electronic health records accessible to patients. J Am Med Inform Assoc 2012; 19(1): 116-120.

2. Cross M. BMA warns against letting patients have access to their electronic records. BMJ 2011; 342: d206

3. Quantin C, Fassa M, Coatrieux G, et al. Giving patients secure $<<$ Google-like $>>$ access to their medical record. Stud Health Technol Inform 2008; 137: 61-67.

4. Gardiner R. The transition from 'informed patient' care to 'patient informed' care. Stud Health Technol Inform 2008; 137: 241-256.

5. Baer D. Patient-physician e-mail communication: the Kaiser Permanente experience. J Oncol Pract 2011; 7(4): 230-233.

6. Flynn D, Gregory P, Makki H, Gabbay M. Expectations and experiences of eHealth in primary care: a qualitative practice-based investigation. Int J Med Inform 2009; 78(9): 588-604.

7. Honeyman A, Cox B, Fisher B. Potential impacts of patient access to their electronic care records. Inform Prim Care 2005; 13(1): 55-60.

8. Vodicka E, Mejilla R, Leveille SG, et al. Online access to doctors' notes: patient concerns about privacy. J Med Internet Res 2013; 15(9): e208.

9. Mandl KD, Szolovits P, Kohane IS. Public standards and patients' control: how to keep electronic medical records accessible but private. BMJ 2001; 322(7281): 283-287.

10. Wiljer D, Urowitz S, Apatu E, et al. Patient accessible electronic health records: exploring recommendations for successful implementation strategies. J Med Internet Res 2008; 10(4): e34.

11. Car J, Sheikh A. Email consultations in health care: 2 - acceptability and safe application. BMJ 2004; 329(7463): 439-442.

12. Meltsner M. A patient's view of OpenNotes. Ann Intern Med 2012; 157(7): 523-524.

13. Bourgeois FC, Taylor PL, Emans SJ, et al. Whose personal control? Creating private, personally controlled health records for pediatric and adolescent patients. J Am Med Inform Assoc 2008; 15(6): 737-743.

14. Rutland CM, Brynhi H, Andersen R, Bryhni T. Developing a shared electronic health record for patients and clinicians. Stud Health Technol Inform 2008; 136: 57-62.

15. Hannan A. Providing patients online access to their primary care computerised medical records: a case study of sharing and caring. Inform Prim Care 2010; 18(1): $41-49$

16. Silvestre AL, Sue VM, Allen JY. If you build it, will they come? The Kaiser Permanente model of online health care. Health Aff (Millwood) 2009; 28(2): 334-344.

17. Nazi KM, Woods SS. MyHealtheVet PHR: a description of users and patien portal use. AMIA Annu Symp Proc 2008; Nov 6: 1182.

18. Department of Health. The power of information: putting all of us in control of the health and care information we need. London: DoH, 2012.

19. Royal College of General Practitioners. Enabling patients to access HER guidance for health professionals. Version 1.0. London: RCGP, 2010. http://uww. rcgp.org.uk/Clinical-and-research/Practice-management-resources/ /media/ Files/Informatics/Health_Informatics_Enabling_Patient_Access.ashx laccessed 19 Dec 2014).

20. Royal College of General Practitioners. Patient online: the road map. London: RCGP, 2013. http://www.rcgp.org.uk/ /media/Files/CIRC/POA/RCGP-Road-Map. ashx laccessed 19 Dec 2014].

21. Higgins JPT, Deeks JJ, eds. Chapter 7: Selecting studies and collecting data. In: Higgins JPT, Green S, eds. Cochrane Handbook for Systematic Reviews of Interventions. Version 5.0.1 [updated September 2008]. The Cochrane Collaboration, 2008

22. Equator Network. Preferred reporting items for systematic reviews and metaanalyses: the PRISMA statement. http://uww.equator-network.org/reportingguidelines/preferred-reporting-items-for-systematic-reviews-and-metaanalyses-the-prisma-statement/ (accessed 19 Dec 2014).

23. Mold F, Ellis B, de Lusignan $\mathrm{S}$, et al. The provision and impact of online patient access to their electronic health records (EHR) and transactional services on the quality and safety of health care: systematic review protocol. Inform Prim Care 2012; 20(4): 271-282.

24. Mold M, Ellis B, de Lusignan S, et al. The provision and impact of online patient access to their electronic health records and transactional services on the quality and safety of health care: systematic review protocol. PROSPERO 2012:
CRD42012003091

25. Stillwell SB, Fineout-Overholt E, Melnyk BM, Williamson KM. Evidence-based practice, step by step: asking the clinical question: a key step in evidence-based practice. Am J Nurs 2010; 110(3): 58-61.

26. Schünemann $\mathrm{H}$, Brozek J, Oxman $\mathrm{A}$, eds. GRADE handbook for grading quality of evidence and strength of recommendation. Version 3.2 [updated March 2009]. The GRADE Working Group, 2009. http://www.guidelinedevelopment.org/ handbook/ laccessed 28 Jan 2015).

27. Guyatt $\mathrm{GH}$, Oxman $\mathrm{AD}$, Vist $\mathrm{GE}$, et al. GRADE: an emerging consensus on rating quality of evidence and strength of recommendations. BMJ 2008; 336(7650): 924-926.

28. GRADE Working Group. Grading of Recommendations Assessment Development and Evaluation (GRADE). http://www.gradeworkinggroup.org/ laccessed 19 Dec 2014).

29. Katz SJ, Moyer CA, Cox DT, Stern DT. Effect of a triage-based E-mail system on clinic resource use and patient and physician satisfaction in primary care: a randomized controlled trial. J Gen Intern Med 2003; 18(9): 736-744.

30. Bergmo TS, Kummervold PE, Gammon D, Dahl LB. Electronic patient-provider communication: will it offset office visits and telephone consultations in primary care? Int J Med Inform 2005; 74(9): 705-710.

31. Katz SJ, Nissan N, Moyer CA. Crossing the digital divide: evaluating online communication between patients and their providers. Am J Manag Care 2004; 10(9): 593-598.

32. Fairhurst $\mathrm{K}$, Sheikh A. Texting appointment reminders to repeated non-attenders in primary care: randomised controlled study. Qual Saf Health Care 2008; 17(5): 373-376.

33. Bergmo TS, Wangberg SC. Patients' willingness to pay for electronic communication with their general practitioner. Eur J Health Econ 2007; 8(2): $105-110$.

34. Kummervold PE, Trondsen M, Andreassen H, et al. [Patient-physician interaction over the internet]. [Norwegian] Tidsskr Nor Laegeforen 2004; 124(20): 2633 2636

35. Lin CT, Wittevrongel L, Moore L, et al. An Internet-based patient-provider communication system: randomized controlled trial. J Med Internet Res 2005; 7(4): e47.

36. Wright A, Poon EG, Wald J, et al. Randomized controlled trial of health maintenance reminders provided directly to patients through an electronic PHR J Gen Intern Med 2012; 27(1): 85-92.

37. Virji, A, Yarnall KS, Krause KM, et al. Use of email in a family practice setting: opportunities and challenges in patient- and physician-initiated communication BMC Med 2006; 4: 18

38. North F, Hanna BK, Crane SJ, et al. Patient portal doldrums: does an exam room promotional video during an office visit increase patient portal registrations and portal use? J Am Med Inform Assoc 2011; 18 Suppl 1: i24-i27.

39. Palen TE, Ross C, Powers JD, Xu S. Association of online patient access to clinicians and medical records with use of clinical services. JAMA 2012; 308(19): 2012-2019

40. Ralston JD, Rutter CM, Carrell D, et al. Patient use of secure electronic messaging within a shared medical record: a cross-sectional study. J Gen Intern Med 2009; 24(3): 349-355.

41. Zhou YY, Garrido T, Chin HL, et al. Patient access to an electronic health record with secure messaging: impact on primary care utilization. Am J Manag Care 2007; 13(7): 418-424.

42. Nagykaldi Z, Aspy CB, Chou A, Mold JW. Impact of a Wellness Portal on the delivery of patient-centered preventive care. J Am Board Fam Med 2012; 25(2): 158-167.

43. Schnipper JL, Gandhi TK, Wald JS, et al. Effects of an online personal health record on medication accuracy and safety: a cluster-randomized trial. J Am Med Inform Assoc 2012; 19(5): 728-734.

44. Matheny ME, Gandhi TK, Orav EJ, et al. Impact of an automated test results management system on patients' satisfaction about test result communication. Arch Intern Med 2007; 167(20): 2233-2239.

45. Delbanco T, Walker J, Bell SK, et al. Inviting patients to read their doctors' notes: a quasi-experimental study and a look ahead. Ann Intern Med 2012; 157(7): 461-470.

46. Oxford Centre for Evidence-Based Medicine. OCEBM Levels of Evidence. 2011. http://uww.cebm.net/index.aspx?o=5653 (accessed 19 Dec 2014).

47. Eng TR. The eHealth landscape: a terrain map of emerging information and communication technologies in health and health care. Princeton, NJ: The 
Robert Wood Johnson Foundation, 2001. http://www.hetinitiative.org/media/pdf/ eHealth.pdf (accessed 19 Dec 2014).

48. Science Panel on Interactive Communication and Health. Wired for health and well-being: the emergence of interactive health communication. Washington, DC: US Department of Health and Human Services, April 1999. http://uww. health.gov/scipich/pubs/finalreport.htm (accessed 19 Dec 2014).

49. Agency for Healthcare Research and Quality. Consumer Health Informatics and Patient Decision-Making. Final Report. Publication 98-N001. Rockville, MD: Agency for Healthcare Research and Quality, 1997.

50. Murray E, Davis H, Tai SS, et al. Randomised controlled trial of an interactive multimedia decision aid on benign prostatic hypertrophy in primary care. BMJ 2001; 323(7311): 493-496.

51. Barry MJ, Fowler FJ Jr, Mulley AG Jr, et al. Patient reactions to a program designed to facilitate patient participation in treatment decisions for benign prostatic hyperplasia. Med Care 1995; 33(8): 771-782

52. Morgan MW, Deber RB, Llewellyn-Thomas HA, et al. Randomized, controlled trial of an interactive videodisc decision aid for patients with ischemic heart disease. J Gen Intern Med 2000; 15(10): 685-693.

53. Gustafson DH, Hawkins R, Boberg E, et al. Impact of a patient-centered, computer-based health information/support system. Am J Prev Med 1999; 16(1): $1-9$

54. Hwang KO, Stuckey HL, Chen MC, et al. Primary care providers' perspectives on online weight-loss programs: a big wish list. J Med Internet Res 2012; 14(1): e16.
55. Simon GE, Ralston JD, Savarino J, et al. Randomized trial of depression followup care by online messaging. J Gen Intern Med 2011; 26(7): 698-704.

56. Hollinghurst S, Peters TJ, Kaur S, et al. Cost-effectiveness of therapist-delivered online cognitive-behavioural therapy for depression: randomised controlled trial. Br J Psychiatry 2010; 197(4): 297-304

57. Chen C, Garrido T, Chock D, et al. The Kaiser Permanente electronic health record: transforming and streamlining modalities of care. Health Aff (Millwood) 2009; 28(2): 323-333.

58. Ye J, Rust G, Fry-Johnson Y, Strothers H. E-mail in patient-provider communication: a systematic review. Patient Educ Couns 2010; 80(2): 266-273.

59. Grover F Jr, Wu HD, Blanford C, et al. Computer-using patients want internet services from family physicians. J Fam Pract 2002; 51(6): 570-572.

60. Andreassen HK, Trondsen M, Kummervold PE, et al. Patients who use e-mediated communication with their doctor: new constructions of trust in the patient-doctor relationship. Qual Health Res 2006; 16(2): 238-248.

61. Hannan A, Webber F. Towards a partnership of trust. Stud Health Technol Inform 2007; 127: 108-116.

62. Pearce C, Bainbridge M. A personally controlled electronic health record for Australia. J Am Med Inform Assoc 2014; 21(4): 707-713.

63. de Lusignan S, Mold F, Sheikh A, et al. Patients' online access to their electronic health records and linked online services: a systematic interpretative review. BMJ Open 2014; 4: e006021 doi:10.1136/bmjopen-2014-006021. 